\title{
PENGOLAHAN DSM DENGAN INTERFEROMETRI SAR (InSAR) ANTARIKSA UNTUK MEKANISME PEMBANGUNAN BERSIH (MPB) PROTOKOL KYOTO
}

\section{DSM Processing with Space Borne SAR Interferometry (InSAR) for Clean Development Mechanism of the Kyoto Protocol}

\author{
M.A. Raimadoya*, B.H. Trisasongko, D. Shiddiq, D.R. Panuju, dan R. Maulida
}

\author{
Radar Analysis Working Group-RAWG (www.rawg.org), \\ Departemen Tanah, Fakultas Pertanian, Institut Pertanian Bogor \\ Jalan Meranti, Kampus IPB Darmaga, Bogor 16680
}

\begin{abstract}
Capacity development in biomass monitoring is a key action in the implementation of Clean Development Mechanism of the Kyoto Protocol in developing country like Indonesia. The objection of this research is to explore the processing of spaceborne InSAR for the construction of Digital Surface Model (DSM). The research successfully completed the process by using two InSAR pairs : ERS-1 \& ERS-2 tandem pass (completed) and ENVISAT repeat pass (coherence only). DSM product, after field validation, will be applied for SAR calibration in relation to biomass and carbon stock estimation.
\end{abstract}

Keywords : CDM, DSM, Kyoto Protocol, spaceborne InSAR

\section{PENDAHULUAN}

Indonesia telah meratifikasi Konvensi Perubahan Iklim PBB (UNFCCC, 1992) melalui UU no. 6/1996, maupun Protokol Kyoto (UNFCCC, 1997) sebagai implementasi atas Konvensi tersebut (sudah disetujui DPR tinggal menunggu diundangkan). Kedua kebijakan internasional ini telah melahirkan unsur Karbon (C) sebagai komoditas baru, yang mulai diperdagangkan dalam Bursa Emisi Internasional pada periode komitmen pertama tahun 2008-2012. Sebagai negara berkembang yang menjadi Peserta dari Konvensi dan Protokol di atas, Indonesia memperoleh peluang untuk mencapai pembangunan berkelanjutan di dalam negeri melalui Mekanisme Pembangunan Bersih (MPB).

Bila didukung dengan Strategi Nasional yang tepat, MPB berpeluang untuk meningkatkan pendapatan masyarakat pedesaan melalui dua sektor : Land Use, Land Use Change and Forestry (LULUCF) dan Energi (Terbarukan). Diperlukan dukungan Pertanian Cermat (Precision Agriculture) dalam operasi MPB di kedua sektor tersebut, karena Karbon yang diproduksi tidak disimpan dalam gudang pada saat diperdagangkan di bursa emisi, tetapi berbentuk tegakan biomasa yang kemungkinan besar berada di kawasan terpencil.

Pertanian Cermat sebagai kebutuhan untuk pelaksanaan MPB, memerlukan DEM (Digital Elevation Model) sebagai model medan 3-D, karena merupakan prasarana informasi utama dalam perencanaan, operasi, maupun pemantauan. Secara spesifik, implementasi MPB/LULUCF sangat bergantung pada dukungan data spasial karena melibatkan kawasan luas dan membutuhkan

\footnotetext{
* Alamat korespondensi:. Tel.: 0251-422325, 0811116355, Fax.: 0251422325, e-mail: mar@rawg.org
}

pemantauan berkala. Dengan demikian penginderaan jauh berperan sangat penting, karena mampu menyediakan pengamatan dengan resolusi spasial dan temporal yang murah dan efisien dibandingkan dengan metode lapangan konvensional. Namun demikian, terdapat kendala inkonsistensi radiometri pada data penginderaan jauh, terutama pada citra optik dan pada topografi yang berbukit sampai bergunung. Khusus pada citra SAR, inkonsistensi radiometri hanya terkait dengan topografi, sehingga memerlukan DEM untuk kalibrasi (Raimadoya dan Trisasongko, 2004). Pengaruh topografi yang sangat menentukan hamburan balik radar pada hutan dan wilayah pertanian juga dikemukakan oleh Luckman (1998b). Teknologi normalisasi topografi untuk kalibrasi citra SAR saat ini masih sangat terbatas. Salah satu metode yang dapat diimplementasikan adalah Metode Luckman (Luckman,1998a). Metode ini membutuhkan informasi DEM yang cukup akurat. Data DEM di Indonesia sendiri sangat jauh terbelakang, sehingga diperlukan upaya khusus untuk pengadaannya, terutama berkaitan dengan MPB/ LULUCF.

Beberapa metode dapat digunakan untuk memproduksi DEM (Li dan Baker, 2001), yaitu: survei lapangan, fotogrametri, Light Detection and Ranging (LIDAR), dan Interferometric Synthetic-Aperture Radar (InSAR). Produk DEM sendiri dibedakan dalam dua jenis, yaitu (Intermap, 2003): Digital Surface Model (DSM) dan Digital Terrain Model (DTM). DSM adalah grid titik elevasi yang mengikuti permukaan dari semua obyek yang berada di atas permukaan topografi, sedangkan DTM adalah grid titik elevasi yang secara murni hanya mengikuti permukaan topografi (obyek di atas permukaan topografi sudah dihilangkan).

Model interferometrik dalam geometri pencitraan operasional (dirgantara atau antariksa) dilakukan dengan 
beberapa cara, yaitu (ESA, 2002a): terobosan tunggal (single pass), terobosan ulang (repeat pass), terobosan silang (cross pass) dan terobosan tandem (tandem pass). Pengolahan InSAR dirgantara di Indonesia dilakukan secara terobosan tunggal melalui kampanye NEXTMap Indonesia, yang tahap pertamanya dimulai Desember 2002 sampai Mei 2003 (Saksono dan More, 2003). Total kawasan yang direkam mencapai $244000 \mathrm{~km}$ persegi, tersebar dalam 561 lembaran peta baku 15' x 15' (skala 1:50 000) dari sistem pemetaan nasional. Dalam penelitian ini InSAR antariksa dilakukan secara terobosan ulang (ENVISAT) maupun terobosan tandem (ERS-1 dan ERS2). InSAR antariksa diperlukan untuk pembangunan kapasitas dalam kemampuan pemantauan MPB khususnya kalibrasi SAR (ESA, 2003), karena semua tahapan pengolahan dilakukan secara lokal. Sementara InSAR dirgantara NEXTMap Indonesia pengolahannya bersifat putar kunci (turn key), sehingga memiliki keterbatasan bagi pembangunan kapasitas lokal dalam mengantisipasi perkembangan satelit SAR di masa depan, maupun dalam implementasi MPB.

Penelitian ini bertujuan untuk mempelajari prosedur pembuatan DSM dengan metode InSAR antariksa. Metode InSAR baik secara antariksa (spaceborne) maupun dirgantara (airborne) secara ilmiah memiliki keunggulan dibandingkan metode lain di atas, khususnya dalam hal berikut: kemampuan ekstraksi informasi 3-D resolusi tinggi, proses pengolahan yang cepat, dan beroperasi hampir secara bebas cuaca. Prosedur verifikasi DSM tidak dibahas dalam naskah ini karena jaringan geoid lokal pada tapak uji tidak tersedia, sehingga hanya didasarkan pada datum elipsoid WGS 1984, yang tidak terkait dengan tinggi ortometris.

\section{BAHAN DAN METODE}

Tehnik InSAR mengambil keuntungan dari kualitas unik citra SAR, yaitu informasi jarak dari sensor ke muka bumi direkam untuk setiap piksel dalam citra SAR. Tidak seperti citra optis, yang hanya mengandung intensitas energi yang diterima sensor, citra SAR mengandung informasi jarak berbentuk fase. Jarak ini secara sederhana merupakan bilangan panjang gelombang dari sumber radiasi pada sensor terhadap titik tertentu di muka bumi. Sensor SAR dapat merekam informasi ini karena, tidak seperti sensor optis, sumber radiasinya aktif dan koheren.

\section{Model Interferometrik}

Sebagian besar pemakaian citra SAR melibatkan peragaan amplitudo dari pantulan citra dan mengenyampingkan unsur fase dari gelombang elektromagnetik. Citra kompleks SLC (Single Look Complex) SAR untuk aplikasi InSAR merekam deteksi sinyal dalam bilangan kompleks baik dalam amplitudo maupun fase. Fase suatu piksel citra point target mewakili suatu pencaran tunggal bersifat deterministik. Pada aplikasi bentangan alam, fase suatu piksel citra merupakan distributed target yang mewakili pencaran ganda (dalam satu sel resolusi). Fase jenis ini terdiri dari bagian statistik yang deterministik dan non-deterministik (ERDAS, 1999). Dengan demikian, fase piksel pada sebuah citra SAR tunggal tidak berguna untuk aplikasi bentang alam, karena informasi jarak mengandung ambiguitas. Sebaliknya, dengan pemilihan suatu geometri pencitraan yang tepat, dua citra SAR dapat direkam dengan komponen fase nondeterministik yang hampir identik. Kedua citra SAR ini dapat saling dikurangkan, menghasilkan hanya suatu perbedaan fase deterministik yang amat berguna dalam menghasilkan DSM. Gambar 1(a) menyajikan model geometrik dasar untuk suatu sistem SAR interferometrik.

Dari Gambar 1(a) terlihat A1 = Antena 1, A2 = Antena $2, \mathrm{Bi}=$ garis pokok (baseline), $\mathrm{R}=$ vektor dari antenna 1 ke titik sasaran, R2 = vektor dari antenna 2 ke titik sasaran, $\Psi=$ sudut antara R1 dan vektor garis pokok (sudut depresi), Zac = tinggi antenna 1. Pada gambar tersebut juga terlihat suatu garis pokok (baseline) Bi yang memisahkan dua antenna, A1 dan A2. Pemisahan ini menyebabkan kedua antenna menyinari kawasan pada sudut depresi yang sedikit berbeda relatif terhadap garis pokok. Dalam hal ini $\Psi$ adalah sudut depresi nominal dari A1 ke sasaran pemencar, relatif terhadap garis pokok. Model mengasumsikan bahwa wahana bergerak pada kecepatan konstan pada arah X sementara garis pokok tetap sejajar terhadap sumbu Y pada suatu ketinggian konstan Zac di atas bidang XY.

Dengan mengasumsikan konfigurasi baku SAR di mana jarak tegak lurus dari SAR ke sasaran tidak berubah, dapat diformulasikan kuantitas kompleks mewakili pasangan citra piksel, P1 dan P2, dari citra1 dan citra2 sebagai rumus [1] dan [2].

$$
P_{1}=a_{1} \cdot e^{j\left(\theta_{1}+\Phi_{1}\right)}
$$

Rumus [1]

$$
\begin{aligned}
& \text { dan } \\
& P_{2}=a_{2} \cdot e^{j\left(\theta_{2}+\Phi_{2}\right)}
\end{aligned}
$$

Rumus [2]

Kuantitas a1 dan a2 mewakili amplitudo dari masingmasing piksel citra. Umumnya magnitude ini adalah hampir sama. Kuantitas $\theta 1$ dan $\theta 2$ adalah komponen acak dari fase piksel. Komponen ini mewakili penjumlahan vektor pantulan dari semua pencaran yang tidak dipisahkan dalam sel resolusi dan termasuk kontribusi dari derau sensor penerima. Dengan disain sistem yang tepat dan geometri perekaman, komponen ini hampir setara. Kuantitas $\Phi 1$ dan $\Phi 2$ adalah kontribusi deterministik terhadap fase dari piksel citra. Fungsi yang diinginkan dari interferometer adalah memberikan pengukuran perbedaan fase $\Phi 1-\Phi 2$.

Perkalian dari satu citra dengan konyugasi kompleks dari citra kedua pada basis piksel dengan piksel menghasilkan perbedaan fase antara piksel terkait dari kedua citra. Produk kompleks ini menghasilkan interferogram I, di mana tanda' menunjukkan operasi konyugasi kompleks:

$$
I=P_{1} \cdot P_{2}{ }^{\prime}
$$

Rumus [3] 


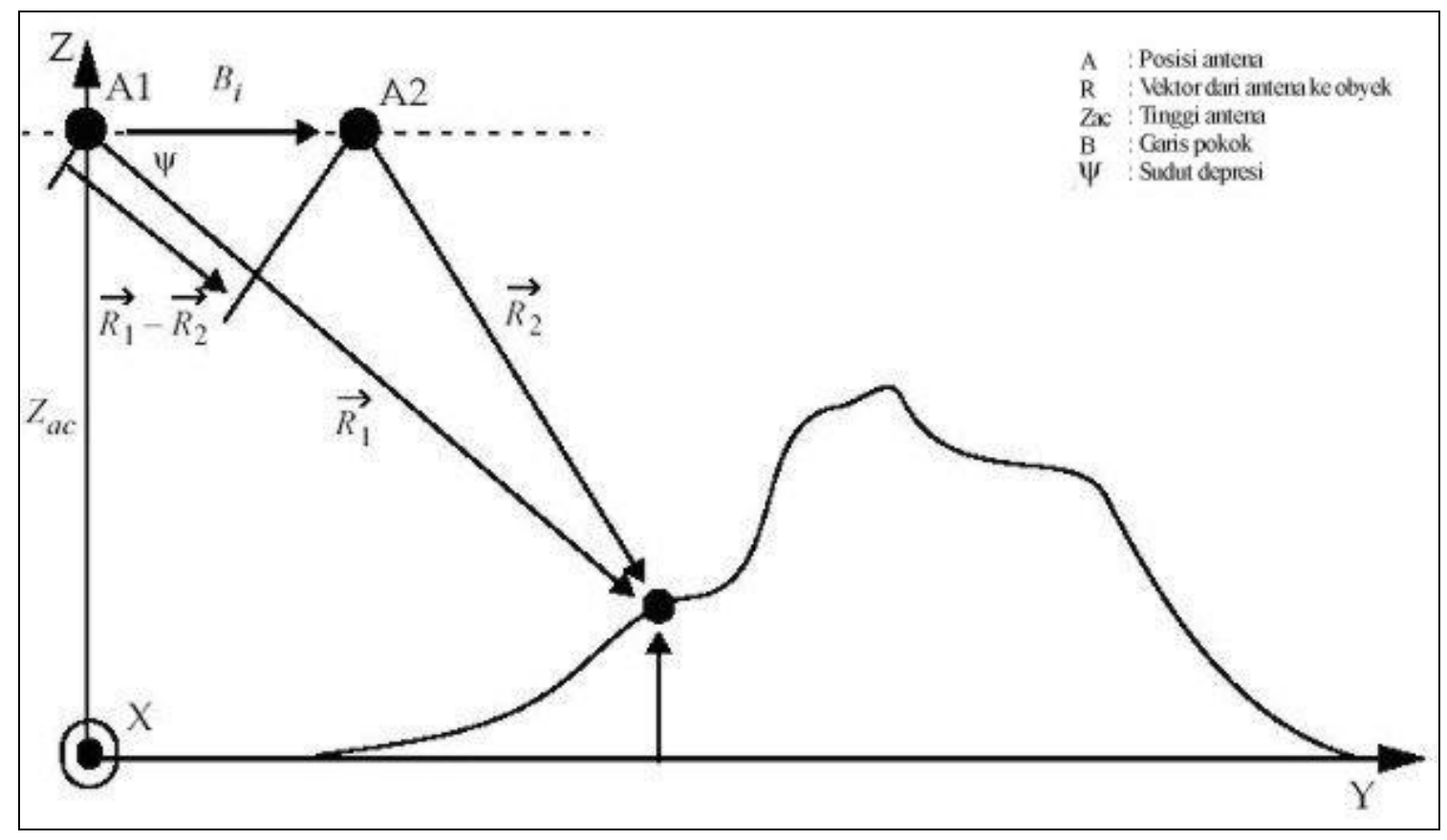

(a)

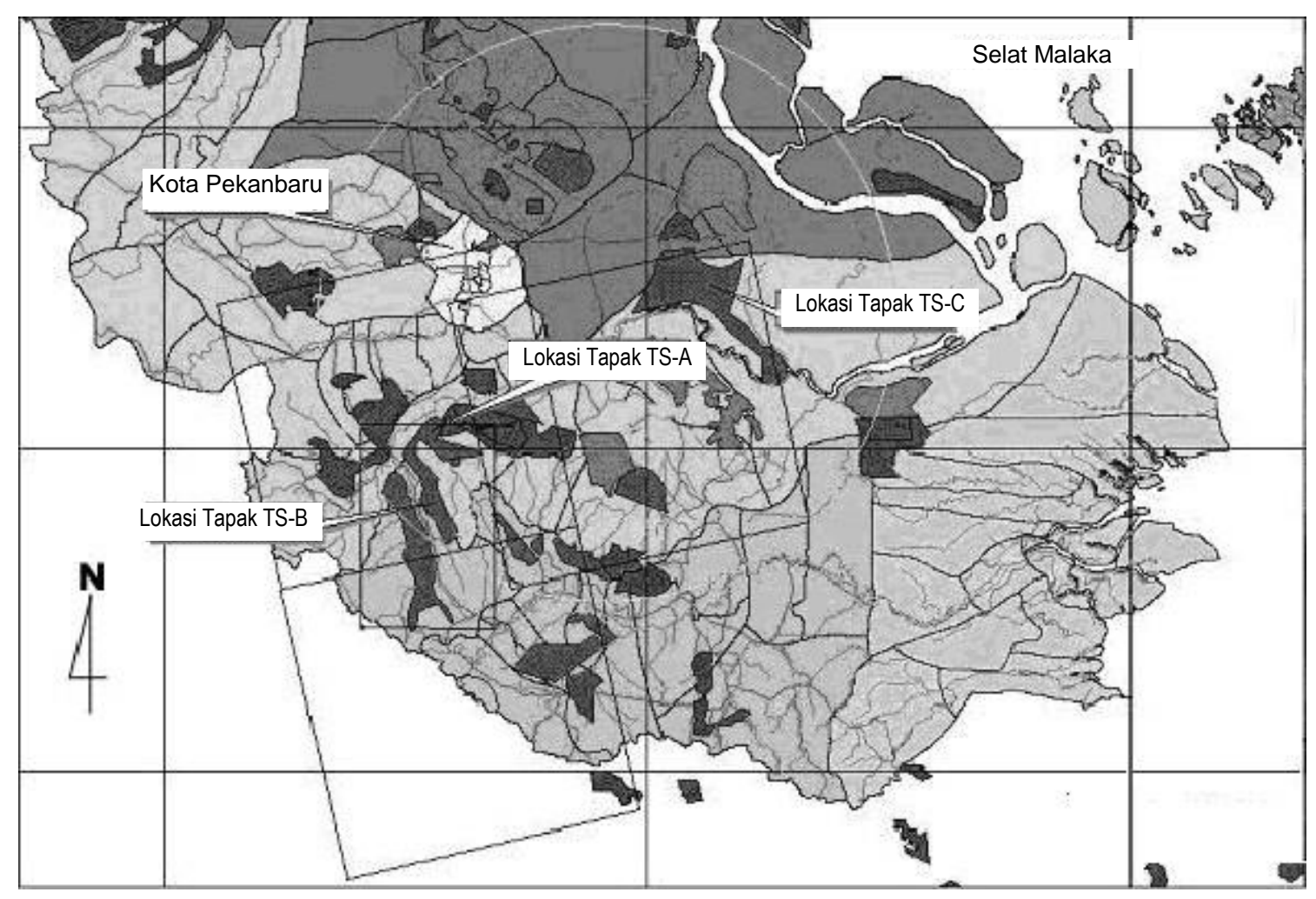

(b)

Gambar 1. Model Geometrik untuk Suatu Sistem Interferometri SAR (InSAR) (ERDAS, 1999) (a), Lokasi Tapak Uji TS-A untuk InSAR Antariksa di Provinsi Riau (b) 
Secara ideal setiap piksel pada interferogram mempunyai bentuk berikut, bila menggunakan $\mathrm{a} 1=\mathrm{a} 2=\mathrm{a}$ :

$$
I=a^{2} \cdot e^{-j\left(\frac{4 \pi}{\lambda}\left(R_{1}-R_{2}\right)\right)}=a^{2} \cdot e^{j \Phi_{12}} \text { Rumus [4] }
$$

Fase dari interferogram menjadi :

$$
\Phi_{12}=\frac{4 \pi\left(R_{2}-R_{1}\right)}{\lambda}
$$

atau :

$$
\Phi_{12} \approx \frac{4 \pi B_{i} \cos (\Psi)}{\lambda}
$$

merupakan kuantitas yang digunakan untuk menurunkan sudut depresi atas titik sasaran relatif terhadap garis pokok, dan akhirnya dapat diperoleh informasi tentang tinggi pemencar relatif terhadap bidang XY.

Fase interferometrik melibatkan banyak radian dari fase untuk pemencar pada sudut depresi lain, karena perbedaan jarak R1 - R2 merupakan banyak panjang gelombang. Dalam praktek, suatu sistem interferometrik tidak mengukur perbedaan total fase piksel. Sebaliknya, sistem hanya mengukur perbedaan fase yang tersisa sesudah mengurangkan semua interval $2 \pi$ penuh yang ada (modul $-2 \pi$ ) atau fase terbungkus.

Untuk menduga sudut depresi aktual terhadap suatu pemencar tertentu, interferometer harus mengukur perbedaan total fase piksel dari banyak siklus. Informasi ini tersedia melalui pembuka bungkusan (unwrapping) pengukuran fase interferometrik, asal dimulai pada suatu lokasi dengan topografi yang diketahui melalui titik kontrol. Gambar 2 menyajikan bagan alur pengolahan InSAR secara umum (Gens, 1998).

\section{Lokasi Penelitian}

Lokasi penelitian berada di Kabupaten Kampar, Provinsi Riau, pada tapak uji ENVISAT TS-A (Gambar 1b), dengan kondisi topografi bergelombang sampai berbukit. Lokasi tapak uji ini merupakan salah satu dari tiga tapak uji terpilih (Raimadoya et al., 2003) dalam kegiatan penelitian Envisat-Indonesia Radar Biomass Experiment (EIRBEX), yang didukung bersama oleh Kementerian Riset dan Teknologi RI (melalui RUTIII/2003), Badan Antariksa Eropa (ESA), dan pihak industri kehutanan PT RiauPulp. Lokasi penelitian biomasa pada hutan tanaman tropika di Indonesia merupakan terobosan penting dalam aplikasi SAR, karena selama ini penelitian SAR sebagian besar terpusat di hutan alam baik untuk kawasan tropika (Amazon) maupun temperate (Siberia).

Sebanyak lima citra SAR antariksa digunakan dalam kegiatan ini, yang disajikan menurut nama satelit, tipe produk, jenis sapuan (khusus Envisat), polarisasi (khusus Envisat), orbit, tanggal rekaman, dan stasiun pengolahan, sebagai berikut : (1) Citra Envisat ASA_IMP_1P, IS-2, V/V, 04874, 20030204, UK-PAF; (2) Citra Envisat ASA_IMS_1P, IS-2,04874, 20030204, UK-PAF; (3) Citra Envisat ASA_IMS_1P, IS-2,05375, 20030311, UK-PAF; (4) Citra ERS-1, SLC3, 25349(D), 20000220, Eurimage; (5) Citra ERS-2, SLC3, 05676(D), 20000221, Eurimage.

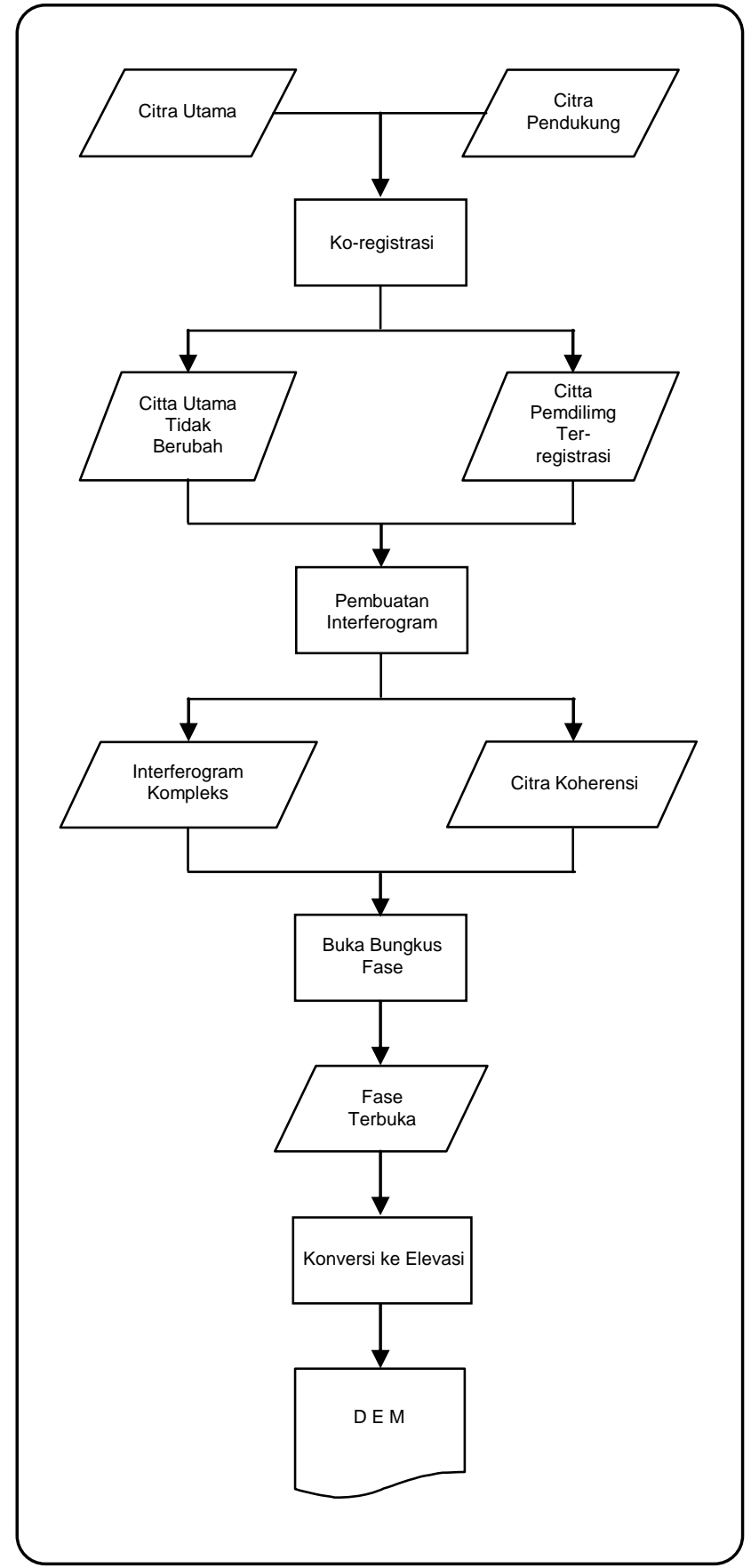

Gambar 2. Bagan alur pengolahan InSAR secara umum (Gens, 1998)

\section{HASIL DAN PEMBAHASAN}

Penelitian dipusatkan pada prosedur pengolahan InSAR antariksa, dan belum termasuk di dalamnya validasi produk DSM, karena untuk validasi memerlukan kegiatan lapangan yang intensif. Sementara pengolahan InSAR sendiri sudah merupakan proses yang kompleks, disebabkan bervariasinya format citra SAR SLC sebagai masukkan awal InSAR. Sementara paket perangkat lunak untuk pengolahan InSAR juga memerlukan perhatian tersendiri, mengingat sensor SAR antariksa yang akan beroperasi dalam dekade pertama milenium ketiga ini meningkat secara sangat pesat. 


\section{Registrasi Piksel}

Mengingat keterbatasan prasarana peta dijital di negara berkembang seperti Indonesia, maka produk DSM dari pengolahan InSAR harus divalidasi secara langsung di lapangan, karena keterbatasan sebaran jaringan titik kontrol. Kendala ini menggiring untuk penggunaan citra SLC SAR yang berasal dari misi ERS atau ENVISAT, dibandingkan Radarsat atau JERS, karena kemampuan menentukan orbit satelit secara cermat (precision orbit). Orbit cermat ini memberikan garis pokok secara akurat untuk pasangan citra InSAR pada geometri pencitraan tertentu, tanpa memerlukan perhitungan dari titik kontrol.

Konsekuensi pemilihan citra SLC SAR yang berasal dari misi ERS atau ENVISAT adalah diperlukan perencanaan perekaman yang sesuai dengan geometri InSAR, dan kompatibel dengan format data kedua satelit tersebut. Untuk keperluan tersebut digunakan paket perangkat lunak DESCW (ESA, 2000). Citra kompleks SLC SAR diperagakan secara khusus dengan bantuan paket EnviView (ESA, 2002b), karena merupakan bilangan kompleks dalam geometri slant range. Artinya tidak dapat ditampilkan oleh peraga citra yang tersedia secara komersial. Proses registrasi piksel sendiri terdiri dari dua tahap: registrasi piksel dan registrasi sub-piksel, dilakukan dengan menggunakan paket BEST (ESA, 2002c). Hasil proses registrasi piksel adalah berupa besaran garis pokok (base line), dengan jalur terbang yang belum dikoreksi, yang perlu dicek silang dengan pangkalan data garis pokok dari perhitungan orbit cermat. Gambar 3 (atas) menyajikan peragaan citra ERS $(50 \mathrm{~km}$ x $50 \mathrm{~km})$ di atas citra ENVISAT, dari proses hasil registrasi.

\section{Pembuatan Interferogram}

Proses pembuatan interferogram dilakukan sesudah tahapan registrasi piksel berhasil dilakukan dengan baik. Proses ini menghasilkan dua citra yaitu citra fase dan citra koherens. Kedua citra ini juga telah disesuaikan pada posisi ground range. Citra ERS pada Gambar 3 (atas) merupakan citra koherens, yang telah disesuaikan pada geometri ground range, sehingga dapat ditempatkan di atas citra ENVISAT precision image (IMP). Proses ini juga menghasilkan koreksi jalur terbang, sehingga memerlukan titik kontrol dengan sebaran yang baik dari pengukuran GPS di lapangan. Proses koreksi ini pada akhirnya menghasilkan orbit terkoreksi dan menghitung residual dari titik kontrol.

Penggunaan yang intensif atas titik kontrol dalam tahapan ini memerlukan bantuan citra IMP ENVISAT yang bergeometri ground range dan dapat ditampilkan untuk pengambilan titik kontrol. Dengan demikian titik kontrol yang digunakan harus dapat diposisikan dengan baik pada citra ENVISAT, yang kemudikan dipindahkan ke citra kompleks SLC SAR ERS melalui proses rektifikasi. Titik kontrol pilihan di atas citra ini kemudian harus diusahakan untuk dapat diukur di lapangan. Pengukuran di lapangan tidak sepenuhnya dapat dilakukan dengan sempurna, karena masalah aksesibilitas dan logistik. Mengingat tingkat kesulitan yang dihadapi pada tahapan ini, maka kawasan seluas $50 \mathrm{~km}$ x $50 \mathrm{~km}$ ini akan dijadikan tapak uji untuk mengvalidasi hasil pengolahan InSAR. Untuk keperluan tersebut maka dilakukan peningkatan kerapatan pengukuran GPS di tapak uji tersebut guna memberikan perbandingan hasil pengolahan InSAR dengan pengamatan langsung di lapangan. Kawasan tapak uji ini bukan merupakan yang ideal, karena kondisi topografi yang terbatas (bergelombang sampai berbukit), tapi sudah sangat menolong dalam pengolahan InSAR antariksa di masa depan.

\section{Buka Bungkus Fase}

Dari rumus [5] ditemukan bahwa penentuan perbedaan fase pada kedua titik adalah kunci untuk mengekstrak tinggi dari fase interferometrik. Sayangnya, suatu sistem interferometrik tidak mengukur perbedaan total fase piksel. Yang diukur hanya perbedaan fase yang tersisa sesudah semua dikurangi dengan interval $2 \pi$ yang ada (modul $-2 \pi$ ). Hal ini menyebabkan nilai fase dari fungsi kontinyu ketika mencapai $2 \pi$ akan dikembalikan ke nilai 0 (fungsi fase terbungkus). Oleh karena itu tugas dari tahapan buka bungkus fase (phase unwrapping) adalah mengambil fungsi fase terbungkus dan merekonstruksikan ke fase kontinyu sebelum melakukan konversi tinggi menjadi DSM. Untuk memudahkan pekerjaan ini, maka proses buka bungkus sebaiknya dimulai dari titik pada baris dan kolom yang mempunyai koherens yang relatif tinggi dan berada di kawasan yang rata. Dari titik awal ini kemudian dilanjutkan keseluruh bagian citra yang lain.

Terdapat dua parameter yang kritikal dalam proses ini, yaitu: correlation cut off dan correlation treshold. Parameter pertama adalah nilai korelasi di bawah mana tidak dilakukan buka bungkus nilai fase. Parameter kedua adalah besaran di mana semua titik dengan nilai korelasi yang berada di atasnya akan diolah lebih dahulu. Pengolahan selanjutnya baru akan dilakukan untuk titik dengan nilai korelasi di bawahnya.

\section{Konversi Tinggi}

Merupakan tahapan terakhir dari pengolahan InSAR, di mana dapat dilakukan pemilihan parameter untuk keluaran DSM yang akan dihasilkan. Parameter tersebut antara lain adalah: nama file keluaran, jarak posting DSM, dan proyeksi peta yang akan digunakan. Gambar 3 (tengah) menyajikan pandangan perspektif dari DSM yang dihasilkan dengan posting $25 \mathrm{~m}$ dan pembesaran vertikal 5X. Gambar 3 (bawah) adalah merupakan DSM yang dilapis dengan citra ENVISAT IMP, dengan pembesaran vertikal 1X. Berbagai tampilan lain yang tidak terbatas seperti kontur, aspek lereng, hillshade dapat dibuat dengan menggunakan paket aplikasi hilir yang menerima grid DSM sebagai masukan. Berbagai tampilan tersebut tidak disajikan di sini, karena di luar konteks penelitian ini. 

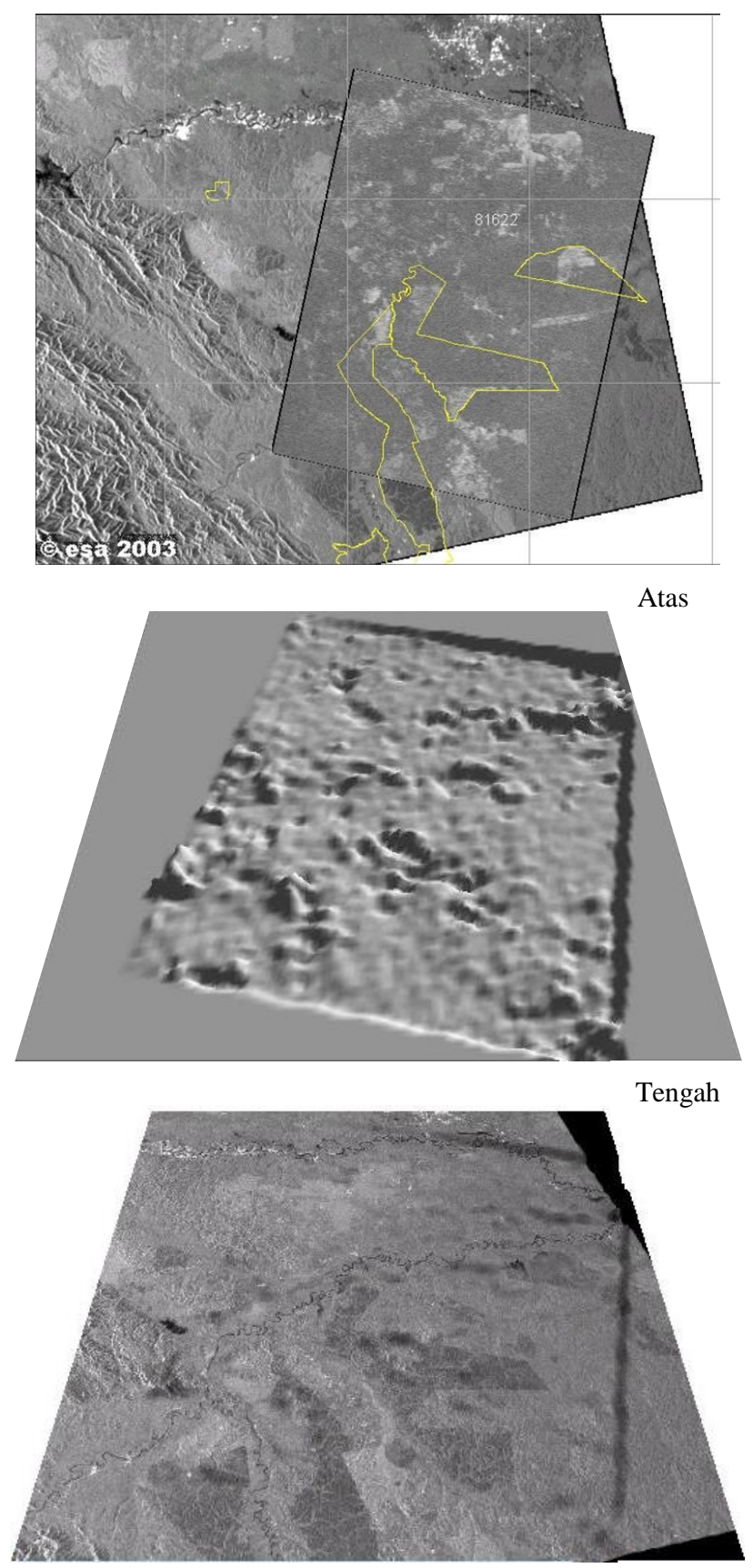

Bawah

Gambar 3. Peragaan Citra Envisat (IMP) Orbit Menaik, dan Citra Koherens ERS-1/2 Tandem Orbit Menurun (Atas); Hasil Pembuatan DEM dari ERS-1/2 Tandem dalam Pandangan Perspektif dengan Eksagerasi Vertikal 5X (Tengah); Citra Envisat (IMP) Digelar di Atas DEM dengan Eksagerasi Vertikal 1X

Unsur penting dalam konversi tinggi adalah garis pokok, yang terbagi dalam dua jenis: garis pokok sejajar dan garis pokok tegak lurus. Nilai garis pokok tegak lurus adalah yang paling penting, dan harus berada dalam kesalahan sekitar $10 \mathrm{~cm}$ jika ingin dihasilkan DSM yang baik. Nilai garis pokok tegak lurus ini dapat ditentukan melalui perhitungan titik kontrol, atau melalui pangkalan data orbit cermat yang memuat data garis pokok untuk pasangan citra InSAR yang digunakan. Untuk memperoleh DSM yang dapat dipertanggung jawabkan, sebaiknya digunakan data garis pokok dari pangkalan data, walaupun tetap dilakukan perhitungan dengan titik kontrol sebagai perbandingan.

\section{KESIMPULAN}

Penelitian ini berhasil melakukan proses pengolahan InSAR pada kuadran 3 citra tandem ERS-1 dan ERS-2, dengan luas kawasan $2500 \mathrm{~km}$ persegi. DSM yang dihasilkan untuk sementara masih menggunakan elipsoid WGS84 sebagai datum vertikal, mengingat tidak tersedianya geoid lokal yang dapat digunakan, sehingga bukan merupakan tinggi ortometris. Namun demikian, ketinggian relatif yang dapat ditunjukkan oleh DSM tersebut dapat segera dimanfaatkan untuk melakukan normalisasi citra SAR terhadap keragaman iluminasi akibat topografi yang bergelombang sampai berbukit.

Keberhasilan ini akan diikuti dengan penetapan tapak uji khusus untuk validasi InSAR yang akan digunakan dalam jangka panjang. DSM tervalidasi yang dihasilkan selanjutnya digunakan untuk kalibrasi citra SAR dalam pemantauan biomasa untuk MPB Protokol Kyoto.

\section{UCAPAN TERIMA KASIH}

Dukungan dana untuk penelitian ini berasal dari Kementerian Riset dan Teknologi RI, Program Riset Unggulan Terpadu Internasional -II/2003, dan PT RiauPulp untuk kegiatan lapangan. Citra SAR Envisat yang digunakan disediakan oleh European Space Agency (ESA), di mana Penulis Utama dan Penulis Kedua melalui seleksi internasional telah dipilih oleh ESA sebagai Principal Investigator dan Co-Investigator, untuk hibah riset AOE869.

\section{DAFTAR PUSTAKA}

ESA. 2000. Display Earth Remote Sensing Swath Coverage for Windows (DESCW). Version 4.3. ESRIN, European Space Agency. Frascati, Italy. 102p.

ESA. 2002a. ASAR Product Handbook. Issue 1.0, 20 August 2002. ESRIN, European Space Agency. Frascati, Italy. $586 \mathrm{p}$

ESA. 2002b. EnviView User Guide. Issue 2.0.7, 21 August 2002. VEGA Group PLC, Welwyn Garden City, Herts, United Kingdom. 141p.

ESA. 2002c. Basic Envisat SAR Toolbox (BEST). Version 3.0, 9 December 2002. ESRIN, European Space Agency. Frascati, Italy. 192p.

ESA. 2003. Absolute calibration of ASAR level 1 products generated with PF-ASAR. Technical Note ENVI-CLVLEOPG-TN-03-0010 Issue 1 Revision 3. ESRIN, Frascati, Italy. 20p.

ERDAS. 1999. ERDAS Field Guide. Fifth Edition. ERDAS Inc., Atlanta, Georgia, USA. p. 326-342.

Gens, R. 1998. Quality assessment of SAR interferometric data. Wissenschaftliche Arbeit der Fachrichtung Vermessungswesen der Universitat Hannover. Germany. $141 \mathrm{p}$. 
Intermap. 2003. Product Handbook and Quick Start Guide. Version 3.2, 15 July 2003. Intermap Technologies Corp., Nepean, Ontario, Canada. 113p.

Li, Xiaopeng and A.B. Baker. 2001. Characteristics of airborne IFSAR elevation data. Intermap Technologies Corp., Nepean, Ontario, Canada. 11p.

Luckman, A.J. 1998a. Correction of SAR imagery for variation in pixel scattering area caused by topography. IEEE Transaction on Geoscience and Remote Sensing. January 1998.

Luckman, A.J. 1998b. The effects of topography on mechanisms of radar backscatter from coniferous forest and upland pasture. IEEE Transaction on Geoscience and Remote Sensing. September 1998.

Raimadoya, M.A., B.H. Trisasongko, D.R. Panuju, D. Shiddiq, and R. Maulida. 2003. Application of Envisat/ASAR for monitoring of tropical forest plantation biomass in Indonesia. Proceedings of FRINGE2003 Workshop :
Advances in SAR Interferometry from ERS and ENVISAT Missions, Frascati, Italy, 1-5 December 2003. ESA Special Publication SP-550.

Raimadoya, M.A. dan B.H. Trisasongko. 2004. EnvisatIndonesia Radar Biomass Experiment (EIRBEX). Progress Report II. Faculty of Agriculture, Bogor Agricultural University.

Saksono, T. dan M. More. 2003. The future maps of Indonesia : Benefit of the leading edge radar interferometry technology. Intermap Technologies Corp., Nepean, Ontario, Canada. $10 \mathrm{p}$.

UNFCCC. 1992. United Nations Framework Convention on Climate Change. 33p. http://www.unfccc.int (diakses 30 Juni 2004).

UNFCCC. 1997. Kyoto Protocol to the United Nations Framework Convention on Climate Change. 23p. http://www.unfccc.int (diakses 30 Juni 2004). 